\title{
Dictamen sobre: El régimen jurídico-administrativo de la rehabilitación y puesta en valor turístico de los "refugios" de Almería construidos durante la guerra civil"**
}

\author{
Raúl Pérez Guerra \\ Profesor titular de Derecho administrativo \\ María Matilde Ceballos Martín \\ Profesora titular de Derecho administrativo \\ María Luisa Roca Fdez-Castanys \\ Profesora contratada de doctor Derecho administrativo \\ Universidad de Almería
}

\begin{abstract}
SUMARIO: 1. EL PATRIMONIO BÉLICO, EN ESPECIAL LOS "REFUGIOS" COMO RECURSO IMPULSOR DE UN NUEVO TURISMO. 1.1. El interés por lo bélico. 1.2. Concepto de refugio. 1.3. Patrimonio Histórico y "refugios". 1.4. La exhibición del dolor. 1.5. La puesta en valor de bienes. 1.6. La puesta en valor y el turismo. 1.7. La apuesta del Ayuntamiento de Almería. 2. ASPECTOS JURÍDICOS DE LAS ACTIVIDADES DE REHABILITACIÓN DE LOS “REFUGIOS” DE ALMERÍA. 2.1. Análisis de las actuaciones. 2.1.1. Inicio: el acuerdo de la Comisión. 2.1.2. Acuerdos previos municipales. 2.1.3. Actuaciones centrales. 2.2. Actividad sancionadora y responsabilidad administrativa. 2.2.1. La responsabilidad. 2.2.2. La naturaleza de los daños. 2.2.3. La reversibilidad o no de los daños. 2.2.3. La sanción aplicada. 3. CONCLUSIONES.
\end{abstract}

\section{EL PATRIMONIO BÉLICO, EN ESPECIAL LOS "REFUGIOS" COMO RECURSO IMPULSOR DE UN NUEVO TURISMO}

\subsection{El interés por lo bélico}

A los setenta años del inicio de la Guerra Civil española se percibe un incremento en el interés por su conocimiento. Los testigos directos de la con-

* Dictamen realizado en virtud del contrato para prestación de servicios solicitado por el Excmo. Ayuntamiento de Almería a la Universidad de Almería, el día 30 de noviembre de 2005. 
tienda prácticamente han desaparecido, lo que conlleva los numerosos intentos de recuperar esa memoria viva que irremediablemente desaparece.

Lejos ya de constituir objeto de confrontación política y cuanto más se aleja cronológicamente, más aumenta el afán de comprender la Guerra Civil desde las perspectivas histórica, científica y patrimonial.

En los últimos años también ha crecido el interés en torno a la recuperación de aquellos objetos muebles o inmuebles relacionados con la contienda española. En este tiempo ha surgido la tendencia de rescatar el Patrimonio Bélico. Todo el Patrimonio procedente de la Guerra Civil, por algunos llamados "arqueología militar" y que incluye los "refugios" bélicos, fortines antitanques, nidos de ametralladoras, trincheras, galerías, túneles, catacumbas, bunkers..., ha sufrido una importante revalorización y ha despertado la atención de muchos estudiosos historiadores, arqueólogos, etc...

Todavía en nuestro paisaje se contemplan algunos restos de aquella etapa. Sin ser considerados monumentos dan fe de una parte de nuestra historia. La continua agresión y olvido que están sufriendo hace que corran el peligro de desaparecer, como ha sucedido con una gran parte de los "refugios" de la Guerra Civil española. En la mayor parte de las ciudades españolas, al término del conflicto bélico, los "refugios" y otras construcciones análogas fueron sellados o bien desaparecieron como resultado de obras posteriores.

\subsection{Concepto de "refugio"}

La primera acepción que del vocablo "refugio" ofrece el Diccionario de la Real Academia de la Lengua es "asilo, acogida o amparo". En efecto, los "refugios" se construyeron durante los años de la Guerra Civil por los Ayuntamientos, o incluso por los propios vecinos, con el ánimo de dotar lugares seguros donde poder resguardarse durante los ataques. Por tanto, su fin último es la protección de los ciudadanos. Su singularidad material estriba en el hecho de que estas construcciones se encuentran ubicados bajo tierra, excavados bajo las calles, jardines y edificios de las ciudades; es decir, en el subsuelo; en algunos casos bajo zonas de dominio privado (casas particulares), y en otras bajo suelo público (calles, plazas, etc...).

Aunque no todos los "refugios" (los hay escolares, de barrio, de carácter privado) presentan el mismo interés para los expertos, hay que destacar la importancia de conservarlos o preservarlos como memoria de una página de las diferentes historias de las ciudades. 


\subsection{Patrimonio Histórico y "refugios"}

Las diversas etapas que se han vivido a lo largo de los años han dejado una amplia herencia cultural compuesta por un enorme conjunto de restos físicos que reciben el nombre de "Patrimonio histórico". Una regla válida y respetada en toda Europa es la importancia de los restos del pasado bélico reciente como parte integrante fundamental del Patrimonio. Así debería considerarse en nuestro entorno, puesto que entre los estudiosos se alcanza la unanimidad sobre el indudable valor de estas construcciones por constituir un importante testimonio de lo acontecido en nuestro país durante los años de la contienda.

En España el campo de la arqueología militar se ha ido desarrollando con gran esfuerzo de los grupos de defensa del Patrimonio histórico. Sin embargo, no hay duda de que la adecuada utilización de estas construcciones implica la coordinación de todas las iniciativas públicas y privadas y esfuerzos de carácter económico, social, cultural y turístico, además de una eficaz organización técnica.

Últimamente historiadores, arquitectos y arqueólogos han reclamado una mayor protección de los "refugios" y otras construcciones bélicas consideradas "documentos históricos" de la defensa pasiva de las ciudades. Algunos estudiosos han alarmado sobre el riesgo de su desaparición en el intento de denunciar la ausencia de protección legal de estos espacios. Sin embargo se encuentran protegidos por la Ley del Patrimonio Histórico Español de 1985, ya que están integrados en el ámbito genérico de protección de la Ley (art. 1 y concordantes) y en la Norma protectora promulgada por la Segunda República en 1933 (véanse los arts. 33 y concordantes), y a cuyo efecto el artículo 1 de la Ley de 1985, dispone que "Integran el Patrimonio Histórico Español los inmuebles y objetos muebles de interés artístico, histórico, paleontológico, etnográfico, científico o técnico. También forman parte del mismo el patrimonio documental y bibliográfico, los yacimientos y zonas arqueológicas, así como los sitios naturales, jardines y parques que tengan valor artístico, histórico o antropológico", añadiendo en su párrafo tercero "Los bienes más relevantes del Patrimonio Histórico Español deberán ser inventariados o declarados de interés cultural en los términos previstos en esta Ley". De manera concreta y con cierta unanimidad, los investigadores consideran que estas construcciones bélicas deberían declararse individualmente como "Bienes de Interés Local o Cultural" por los municipios, como única vía de protección del recuerdo material e histórico de una etapa de nuestro pasado. 


\subsection{Exhibición del dolor}

La conservación del patrimonio debe tener como objetivo principal ofrecerlo al público, situándolo en un contexto adecuado que pueda servir para comprender la realidad que corresponda. Una vía idónea es el impulso de políticas realistas de "musealización” y de divulgación. Las tendencias actuales de la museística plantean una concepción diferente del concepto de museo y de conservación de patrimonio. Se trata de la idea de "ecomuseo", que plantea la exposición del patrimonio sin sacarlo de su lugar de origen y que sirve para acceder de manera mucho más directa a la realidad histórica.

Los museos bélicos y los lugares del dolor están en alza. Los campos de concentración que se han convertido en museos son buena prueba de ello. Entre los lugares y las curiosidades que ofrece la ciudad de Berlín, al que visita la ciudad, se encuentra "el mundo subterráneo de Berlín": Oscuridad, frío, humedad y estrechez -no son pocos los berlineses y visitantes que pagan por todo ello-. "refugios", túneles, guerra fría", así se llama la excursión organizada que Berlín Tourismus Marketing ofrece en su página web.

En esta misma línea las ciudades españolas de Barcelona y Cartagena, cuentan ya con sus propios museos bélicos: recovecos de pasadizos y bóvedas que en el pasado acogieron la vida cotidiana de muchos ciudadanos que se ocultaban de las bombas que caían sobre la ciudad y que hoy día se vuelve a rememorar con un itinerario que nos transporta a un escenario bélico efectivizado con los recursos audiovisuales y de la escena. De esta manera, el Ayuntamiento de Almería ha recogido el testigo de estas iniciativas y se ha propuesto, con gran acierto, valorizar los "refugios" de la Guerra Civil española de la ciudad otorgándoles también un aprovechamiento turístico y cultural, en reconocimiento de un período histórico y social de gran importancia.

No hay duda de que esta iniciativa municipal es un buen ejemplo de la puesta en valor de bienes que pueden perderse para las futuras generaciones. La puesta en valor del Patrimonio Histórico-Cultural de Almería produce efectos positivos en beneficio de todos. Ayuda a mejorar la imagen turística de la ciudad, refuerza los principales rasgos de identidad de los almerienses y ayudará al desarrollo económico del municipio.

\subsection{La puesta en valor de bienes}

El término "puesta en valor" tiende a hacerse cada día más frecuente entre los expertos. Según las Normas de Quito de 1967 poner en valor un bien 
histórico o artístico equivale a habitarlo en las condiciones objetivas y ambientales que, sin desvirtuar su naturaleza resalten sus características y permitan su óptimo aprovechamiento. La puesta en valor debe entenderse que se realiza en función de un fin trascendente (histórico, cultural, ambiental, paisajístico, turístico...), contribuyendo al desarrollo económico de la zona. Es decir se trata de incorporar a un potencial económico un valor actual: en palabras de esa Declaración "poner en productividad una riqueza inexplotada mediante un proceso de revalorización que lejos de mermar su significación puramente histórica o artística, la acrecienta, pasándola del dominio exclusivo de minorías eruditas al conocimiento y disfrute de mayorías populares". De otra parte, la puesta en valor de un determinado bien -histórico o artísticoejerce una beneficiosa acción que se refleja sobre el perímetro urbano en que éste se encuentra emplazado y aún desborda esa área inmediata, extendiendo sus efectos incluso a zonas más distantes. Esos bienes representan, por tanto, un valor económico susceptibles de erigirse en instrumentos de progreso; constituyen también recursos económicos al igual que otras riquezas que se explotan. Esto es, importantes son los diferentes impactos que producen la puesta en valor de un determinado bien: socioeconómicos, culturales, históricos y turísticos.

\subsection{La puesta en valor y el turismo}

Los valores propiamente culturales o históricos no se desnaturalizan ni comprometen al vincularse con los intereses turísticos. Muy al contrario, razones culturales educativas y sociales justifican el uso de la riqueza patrimonial en función del turismo. El aprovechamiento integral de los recursos endógenos de una determinada zona es uno de los elementos decisivos a tener en cuenta hacia su desarrollo. La oferta turística y la creación de nuevos productos turísticos que potencien los recursos naturales y patrimoniales ya existentes, es uno de los sectores susceptibles de formar parte de proyectos de desarrollo. Es preciso disponer de una oferta turística conjunta del territorio, que sea complementaria, y se autoenriquezca, permitiendo desestacionalizar la oferta turística y ampliando la gama de productos y servicios ofertados.

Por tanto, en este caso, el proyecto que se presenta por el Ayuntamiento aspira a la revalorización de estos bienes otorgándoles un aprovechamiento turístico que propicie la creación de nuevos productos turísticos a favor del turismo cultural. Al tradicional turismo de sol y playa se une un emergente turismo cultural cuyo principal atractivo es el Patrimonio Cultural, Científico, Técnico o Histórico. En las últimas décadas el aumento del nivel de vida y del nivel cultural y educativo de los turistas ha generado cambios importantes en 
el comportamiento de los mismos. El cambio producido en el turismo masivo ha provocado el aumento del interés por restos materiales históricos. Se ha desarrollado ampliamente el turismo cultural que constituye la vuelta a los orígenes del turismo: en el siglo XVIII el objetivo del viajero era convertir su viaje en un instrumento de provecho, de formación y de cultivo intelectual; durante el siglo XIX las preocupaciones culturales siguen presentes en el interés de esos sujetos. Es después de la Segunda Guerra Mundial cuando se produce la masificación del turismo: el viaje se convierte en una forma de descanso y se difunde el turismo de vacaciones.

Finalmente, en la actualidad, de otra parte y junto al turismo de sol y playa, el turismo bélico (como un tipo de turismo) puede considerarse como una rama reciente del turismo cultural que está teniendo gran desarrollo en los últimos años. Consiste en visitas a lugares bélicos, ya en desuso, que complementan a otras rutas tradicionales histórico-artísticas. Téngase en cuenta que este turismo comenzó en España incluso durante el mismo desarrollo de la Guerra Civil, ofertándose a los turistas que visitaban nuestro país, rutas de guerra, en las que se podían apreciar las trágicas circunstancias bélicas en el mismo escenario de la guerra. Los proyectos de puesta en valor plantean la posibilidad de revitalizar zonas mediante el desarrollo de este turismo y en especial que puedan adaptarse a los usos turísticos estas construcciones de defensa pasiva. Sin embargo, hay que destacar también que el desarrollo de esta clase de turismo no se produce sin obstáculos: la conversión de aquellas instalaciones en un atractivo turístico exige inversiones que no siempre están disponibles o cuya rentabilidad se desconoce. A ello se añaden barreras cognitivas: este tipo de bienes tienen un especial valor cultural aunque carezcan de valores estéticos, y la visita a este tipo de instalaciones puede resultar impactante; barreras económicas: el coste de la rehabilitación o restauración suele ser elevado; barreras legales o administrativas: falta de coordinación y colaboración entre las Administraciones Públicas; y barreras físicas: generalmente, difíciles accesos a estas construcciones.

\subsection{La apuesta del Ayuntamiento de Almería}

En cualquier caso, manifestada la voluntad del Ayuntamiento de Almería de contribuir a la protección y difusión del "Patrimonio histórico-bélico" de la capital, mediante la revalorización histórica, cultural y estética de los "refugios" locales de la Guerra Civil española, hay que concluir con el incuestionable impacto, sustancialmente positivo, que ésta iniciativa supone para el fortalecimiento y difusión del turismo cultural de la ciudad de Almería y para el conocimiento de su propia historia. Y es que hay que recordar lo que, en pala- 
bras de algunos estudiosos de la materia, implica la materialización de este "propósito el proyecto de recuperar los refugios sirve de testimonio y recuerdo a unos hechos trágicos que nunca debieron suceder pero que forman parte de nuestro pasado. Una etapa trágica que sólo han vivido los veteranos de nuestra ciudad, pero que nuestros hijos y nietos han de conocer y respetar. Hay que conocer la historia para no repetirla".

\section{ASPECTOS JURÍDICOS DE LAS ACTIVIDADES DE REHABILI- TACIÓN DE LOS “REFUGIOS” DE ALMERÍA}

\subsection{Análisis de las actuaciones}

\subsubsection{Inicio: el acuerdo de la Comisión}

La puesta en valor de los "refugios" de la Guerra Civil de Almería se inicia con el acuerdo de la Comisión de Seguimiento del Plan de Dinamización Turística del Municipio de Almería.

La Comisión de Seguimiento del Plan de Dinamización Turística del Municipio de Almería, creada en virtud del Convenio de Colaboración suscrito el 29 de septiembre de 2003, no es un órgano municipal ni tiene personalidad jurídica y está constituida por representantes de la Secretaría de Estado de Comercio y Turismo del Ministerio de Economía, la Consejería de Turismo y Deporte de la Junta de Andalucía, el Ayuntamiento de Almería y la Asociación Provincial de Empresarios de Hostelería de Almería. Esta Comisión, presidida por el Alcalde-presidente o persona en quién delegue, tiene la competencia de aprobar la actuación a llevar a cabo en el seguimiento del Plan de Dinamización Turística. Por ello, la puesta en valor de los "refugios" de Almería en el marco del citado Plan exige su aprobación por los integrantes de la Comisión, acuerdo éste que fue tomado por unanimidad el día 7 de febrero de 2005 tal y como exige la cláusula octava del Convenio de 29 de septiembre de 2003.

\subsubsection{Acuerdos previos municipales}

Para la materialización de dicho acuerdo se aprobaron dos tipos de actuaciones distintas:

A) Con carácter previo, se decide ejecutar las obras de limpieza y consolidación de los "refugios" de Almería, adjudicadas aquéllas por las Resolucio- 
nes de la Alcaldía-Presidencia de 4, 16 y 22 de marzo y 5 de abril de 2005, respectivamente. La adjudicación de estas obras es una competencia que se atribuye al alcalde en el artículo 21.1.d), f), ñ) y o) de la Ley Reguladora de las Bases del Régimen Local de 2 de abril de 1985; cabiendo su delegación en virtud del apartado 3 de este mismo precepto.

En esta primera fase se procede a la redacción de los correspondientes proyectos geotécnicos de seguridad y salud y de ejecución del centro de visitantes de los "refugios" de Almería. Paralelamente se realiza la limpieza y desescombro de los residuos y lodos que existen en el interior de los "refugios", lo que conlleva la apertura de dos de los accesos originales construidos en su día, en concreto los ubicados en las Plazas Manuel Pérez García y Pablo Cazard, ambas en la ciudad de Almería.

B) En un momento posterior, una vez reunidos los preceptivos proyectos y ejecutadas la limpieza y consolidación de los "refugios", se acuerda proceder a la rehabilitación y accesos de los citados "refugios". La adjudicación de estas actuaciones se llevó a cabo por la Junta de Gobierno Local de 28 de junio de 2005, tal y como corresponde a tenor del artículo 23.1.b) de la Ley Reguladora de Bases del Régimen Local, en su modificación por la Ley 57/2003, de 16 de diciembre, de medidas para la modernización del Gobierno Local.

\subsubsection{Actuaciones centrales}

La Plaza Manuel Pérez García se encuentra ubicada dentro del área delimitada como Conjunto Histórico, declarado Bien de Interés Cultural por Decreto 107/1999, de 4 de mayo. Su declaración como tal implica que sea objeto de una especial protección. El artículo 20, párrafo primero, de la Ley 16/1985, de 25 de junio, del Patrimonio Histórico Español atribuye al municipio, en que se encontraren los Bienes declarados de Interés Cultural, la competencia para formular un Plan Especial de protección del área afectada por la declaración, u otro instrumento de planeamiento de los previstos en la legislación urbanística.

El Ayuntamiento de Almería formula estas medidas de protección en el Plan General de Ordenación Urbana de Almería -informado favorablemente por la Dirección General de Bienes Culturales en la Resolución de 12 de enero de 1999- y en la normativa de protección del Conjunto Histórico-Arqueológico. En concreto, esta zona se incluye en un nivel II, protección normal, que es el asignado a las áreas urbanas con una elevada probabilidad de existencia de restos arqueológicos de valor cultural. Las condiciones particulares 
de protección para este nivel exigen la realización de un Proyecto de Seguimiento Arqueológico y la autorización de la Administración competente, es decir la de Cultura, con carácter previo al inicio de las obras que supongan una remoción de tierra en la superficie o en el subsuelo.

Es precisamente la adaptación de los accesos a los "refugios" a unas determinadas condiciones sobre seguridad lo que obliga a colocar un elevador en la entrada de los mismos. La propia naturaleza de la obra conlleva la remoción de tierra a la que alude el Plan General de Ordenación Urbana de Almería en su artículo 9.

El Ayuntamiento de Almería, con competencia, desde la aprobación definitiva de las medidas de protección, para autorizar directamente las obras que afecten a inmuebles y en cumplimiento de aquellas condiciones, presenta el día 20 de abril de 2005, ante la Delegación Provincial de la Consejería de Cultura de la Junta de Andalucía, el Proyecto de Seguimiento Arqueológico de las obras de los "refugios" de Almería a realizar en la Plaza Manuel Pérez García. Este mismo proyecto fue autorizado por la Delegación de Cultura el 21 de abril del mismo año, así como el Informe Preliminar del Seguimiento Arqueológico de aquellas obras cuyo visto bueno por esa Delegación aconteció el día 9 de mayo de 2005.

La intervención arqueológica preceptiva -a la que hace mención el Proyecto de Seguimiento Arqueológico- se desarrolló durante los días 25 de abril a 7 de mayo, seguida de la presentación por parte del Ayuntamiento de Almería y ante la Delegación de Cultura del Informe correspondiente el referido día 9 de mayo de 2005, esto es cuarenta y nueve días antes de la adjudicación, por la Junta de Gobierno Local, de las obras de rehabilitación y accesos a los "refugios" de Almería ocurrida el 28 de junio de 2005.

En el análisis de las actuaciones se pone de manifiesto que el Ayuntamiento de Almería no ha incumplido las medidas de protección establecidas en el artículo 9 del Plan General de Ordenación Urbana de Almería. La Corporación realiza el seguimiento arqueológico, autorizado por la Delegación de Cultura, antes de proceder a la adjudicación de las obras de accesos a los "refugios", que son las que implican una remoción de tierra del subsuelo comprensible, y no la mera limpieza de los "refugios" realizada en una fase anterior.

En el peor de los casos, aún considerándose que el proyecto y la intervención arqueológica se realizaron con posterioridad al inicio material de las obras de acceso a los "refugios", la tramitación seguida por el Ayuntamiento 
de Almería con ocasión de las referidas obras no sería contraria a la normativa de protección contenida en el Plan General de Ordenación Urbana sino que, en todo caso, se podría mantener que el procedimiento adolece de un defecto de forma, subsanado tras la presentación, por aquella Corporación y ante la Delegación Provincial de Cultura, del Proyecto de Seguimiento Arqueológico. Proyecto que, téngase en cuenta, fue solicitado y autorizado por la misma Delegación Provincial los días 7 y 21 de abril de 2005, respectivamente. Todas estas actuaciones inducen a considerar que el proceder del Ayuntamiento es aceptado y consentido por la Administración competente en Patrimonio, ya que la Delegación de Cultura solicita -el 7 de abril de 2005-, acepta la presentación -el 20 de abril de 2005- y autoriza -el 21 de abril del mismo año- el proyecto de seguimiento arqueológico después de haber comprobado varios días antes -el 6 de abril- "in situ" la producción de presunto daño a restos arqueológicos, originados con la apertura de un hueco que facilite la colocación de un ascensor para acceder a los "refugios", tal y como obra en el Informe de los técnicos de la Delegación de Cultura firmado el mismo día.

En efecto el día 6 de abril de 2005 se realiza la visita de los técnicos de la Delegación de Cultura manifestando en su Informe que la realización de un hueco para ubicar "un ascensor que comunique la superficie con las galerías de los "refugios" que se pretenden rehabilitar han dañado restos constructivos que posiblemente se correspondan con el sistema defensivo del siglo XI". El mismo día la Delegación de Cultura ordena la inmediata paralización de las actuaciones que se están llevando a cabo por el Ayuntamiento en la Plaza Manuel Pérez García.

Los días 7, 8 y 9 de abril la citada Delegación solicita al Ayuntamiento de Almería el Proyecto de Seguimiento Arqueológico, Proyecto que fue recibido, en su registro, el 20 de abril del mismo año y autorizado al día siguiente.

A los pocos días, el 5 de mayo, la Delegada Provincial de Cultura emite Resolución levantando la paralización de las citadas actividades y, tan sólo cuatro días más tarde, el Ayuntamiento de Almería presenta el Informe del resultado del seguimiento arqueológico realizado tres días antes.

Finalmente, el 16 de mayo, la Delegación Provincial de la Consejería de Cultura incoa expediente sancionador contra el Ayuntamiento de Almería por presunta infracción administrativa contra el Patrimonio Histórico por las actuaciones realizadas en la Plaza Manuel Pérez García. Según el artículo 3 de la Ley 1/1991, de 3 de julio, del Patrimonio Histórico de Andalucía "correspon- 
de a la Comunidad Autónoma de Andalucía la competencia exclusiva sobre el Patrimonio Histórico Andaluz, sin perjuicio de las competencias que correspondan al Estado o estén atribuidas a la Administración Local”, competencias entre las que, entendemos, caben incluir la protección y conservación del Patrimonio Histórico mediante una colaboración estrecha basada en relaciones recíprocas, de plena comunicación y cooperación y asistencia mutua entre las distintas Administraciones Públicas de la Comunidad andaluza como dispone el artículo 4.2 de 3 de julio de 1991. En las actuaciones referidas durante los meses de abril y mayo de 2005 se deja entrever la falta de unidad de criterio en el proceder de la Delegación de Cultura al levantar la paralización de las obras -y por tanto permitir la actividad del Ayuntamiento- con anterioridad a la incoación del expediente sancionador y no a un mismo tiempo, en la misma Resolución de incoación del expediente como exige el artículo 42.2 de la Ley de 3 de julio de 1991. Asimismo hay que poner de manifiesto que, a tenor del deber de protección y conservación del Patrimonio Histórico de Andalucía que se le atribuye legalmente a la Administración competente en Cultura en los artículos 3.1 y 4.2 de la Ley de Patrimonio anteriormente citada, la paralización de las obras es una medida cautelar, que quizás, debiera haberse mantenido hasta una comprobación definitiva de la naturaleza de los presuntos daños ocasionados por las actividades del Ayuntamiento en la Plaza Manuel Pérez García.

Ante la incertidumbre, producida por lo que podría constituir un hallazgo para el Patrimonio Histórico de Almería, no hubiera sido desacertado alcanzar soluciones armonizadoras. La Administración persigue un único objetivo fundamental que es servir con objetividad los intereses generales de la sociedad. Así, y a tenor de las competencias atribuidas a la Comunidad Autónoma andaluza sobre esta materia -el Patrimonio Histórico de Andalucía-, de las reconocidas a los Ayuntamientos en la misma Ley, y también en virtud del principio de cooperación interadministrativa que postula la Ley 30/1992, de 26 de noviembre, del Régimen Jurídico de las Administraciones Públicas y del Procedimiento Administrativo Común, e incluso la misma Ley del Patrimonio Histórico de Andalucía, se podría haber proyectado una fórmula conciliadora de colaboración entre ambas Administraciones optando por una Comisión integrada, además de por los arqueólogos oficiales de cada una de las Administraciones, por algunos expertos de reconocida experiencia en la materia, con el único objetivo de lograr una unidad de criterios en la salvaguarda de esos bienes que, en definitiva, garantizan el interés general, y cuyo valor respectivo no puede olvidarse por ninguna de las Administraciones interesadas, adoptando las previsiones necesarias para compatibilizar la tutela de todos los bienes afectados. 


\subsection{Actividad sancionadora y responsabilidad administrativa}

La propuesta de Resolución de la Delegación Provincial de Almería en la que se sanciona con una multa de 120.000 euros, al Ayuntamiento de Almería por las actividades realizadas con motivo de la rehabilitación y acondicionamiento de los "refugios" de la Guerra Civil, se ha confirmado, con posterioridad, en la Orden de la Consejería de Cultura por la que se resuelve el expediente sancionador contra aquella Corporación Local como responsable de una infracción administrativa tipificada en el artículo 76.1.e) de la Ley 16/1985, de 25 de junio, de Patrimonio Histórico Español.

El artículo 46 de la Constitución española dispone que los poderes públicos garantizarán la conservación y promoverán el enriquecimiento del Patrimonio Histórico y de los bienes que lo integran cualquiera que sea su régimen jurídico y su titularidad. A lo que añade que la Ley Penal sancionará los atentados contra este Patrimonio. Tanto la potestad sancionadora del poder judicial (a través de la jurisdicción penal) como la de la Administración Pública constituye manifestaciones del poder de coacción inherente al Estado para mantener el orden y la paz social. No obstante, ese poder de coacción del Estado se atribuye, por el legislador, al poder ejecutivo o al poder judicial en función de consideraciones históricas, políticas y sociales. Pues bien, en virtud del principio de la mínima intervención penal, solamente los atentados más graves contra el orden social son constitutivos de conductas delictivas y, por tanto, tipificadas como tales en el Código Penal, quedando reservada su sanción a la jurisdicción penal. Descartado es, en este caso, que las actividades que han provocado la tramitación del expediente sancionador contra el Ayuntamiento de Almería, puedan constituir hechos delictivos, básicamente por dos razones:

Primero, no concurren, desde el punto de vista jurídico, los elementos esenciales que conforman el tríptico sobre el que se asienta el concepto del delito como conducta típica, antijurídica y culpable, tal y como exigen los tipos penales que sobre el Patrimonio Histórico se tipifican en los artículos 321 a 324 del Código Penal.

Segundo, la propia normativa administrativa, la Ley del Patrimonio Histórico Español de 25 de julio de 1985 relaciona una serie de supuestos de infracciones administrativas entre las que podría incluirse la posible infracción que da cobertura a las actividades realizadas por el Ayuntamiento con motivo de la rehabilitación de los citados "refugios" -artículo 76.1.e)-. 
Esta última es la que ha llevado a la Administración Autonómica en la materia a incoar el expediente sancionador que ha culminado finalmente con la sanción administrativa de la Consejera de Cultura de la Junta de Andalucía al Ayuntamiento y en el que se asegura que la discusión radica, precisamente, en que los hechos son constitutivos de infracción administrativa. El hecho de que las citadas actividades hayan sido consideradas como constitutivas de una infracción administrativa -por la Consejera de Cultura-, excluye la intervención del Derecho Penal en este tema, prevaleciendo, y tras la aprobación de la Constitución española de 1978, uno de los principios fundamentales que inspiran el ordenamiento jurídico español, y en concreto el Derecho Sancionador, nos referimos al principio de "non bis in idem" a partir de cual ya no cabe la doble imposición de sanciones penales y administrativas por la comisión de unos mismos hechos cuando se aprecie identidad del sujeto y fundamento (artículo 133 de la Ley 30/1992, de 26 de noviembre). Por otro lado, de haberse apreciado indicios de comisión delictiva en las polémicas actuaciones, objeto de denuncia por la Delegación Provincial de Cultura y el Grupo Municipal Socialista del Ayuntamiento ante la Fiscalía de Almería, se habría paralizado el procedimiento administrativo en tanto en cuanto el proceso judicial estuviere pendiente de Resolución; cosa que finalmente no ha ocurrido y que ha precipitado el punto y final de dicho procedimiento administrativo.

\subsubsection{La responsabilidad}

Examinado, en otro lugar de este Informe, nuestro parecer sobre las actividades realizadas por el Ayuntamiento en la Plaza Manuel Pérez García, el interés radica ahora, no obstante, en saber si cabe exigir responsabilidad -y hasta donde- por los presuntos daños causados con motivo de aquéllas.

En el Derecho sancionador administrativo uno de los requisitos que requiere la imposición de sanciones es el de la culpabilidad y tipicidad, lo que quiere decir que la contravención administrativa -si la hubiere- objeto de sanción ha de ser atribuible al sujeto a título de dolo o culpa y que el hecho esté claramente tipificado en la Ley tuteladora. No se dan aquí estas circunstancias tal y como se demuestra en el proceder municipal a lo largo de estos meses. La tipificación del presunto acto infractor exige un profundo estudio arqueológico, técnico e histórico que valore de forma indubitada los valores de ambos bienes (muralla y "refugios") y compatibilizar la coexistencia y valoración de los mismos, ya que no puede afirmarse "a priori", y de forma absoluta, que uno de ellos debe prevalecer sobre el otro, porque supondría una actuación arbitraria en perjuicio del interés general, que es el fundamento o causa que justifica la fiscalización y, en su caso, la anulación del acto administrativo afec- 
tado de presunta nulidad, con las correspondientes consecuencias de todo género. Por otro lado, el Ayuntamiento, cabe afirmar, no ha actuado con dolo o culpa y por tanto solamente cabría estudiar una responsabilidad objetiva -como es la responsabilidad patrimonial de la Administración- e, incluso, podría hablarse de una "responsabilidad por riesgo creado" como contrapartida que asume el sujeto que puede realizar una actividad que, siendo útil a la sociedad (como es la rehabilitación de los "refugios" olvidados de Almería), implica también un riesgo, y por ello atiende más a indemnizar a los perjudicados -si los hay- que a buscar culpables del daño cuando éste va unido a actividades autorizadas. No hay duda de que estas obras son de utilidad histórica, cultural y social y de que están autorizadas preceptivamente por los órganos competentes: la Comisión de Seguimiento (la rehabilitación de los "refugios"), el Alcalde (las obras de limpieza) y el Consejo de Gobierno (la ejecución de las obras de los accesos), además de la autorización a posteriori de la Delegación Provincial de Cultura.

En el presunto supuesto teórico de responsabilidad del Ayuntamiento habría que acreditar los daños y aplicar los principios de coordinación, buena fe y confianza legítima (artículo 3.1 de la Ley 30/1992, de 26 de noviembre, LRJAP y PAC) pues el Ayuntamiento podría ser responsable por "culpa in vigilando" respecto de las actividades de sus empleados o contratistas al actuar presuntamente de forma impropia o inadecuada al ejecutar la obra o el trabajo contratado y que crea un riesgo de daño que el Ayuntamiento-empleador no podía razonablemente prever, hablándose, por tanto, adecuadamente de negligencia colateral. Igualmente la misma imputación podría hacerse a la Administración autonómica por su falta de coordinación y vigilancia respecto de los bienes cuya tutela le corresponde.

\subsubsection{La naturaleza de los daños}

Otro tema controvertido es el de la naturaleza de los daños causados con motivo de estas obras. Aunque en algún lugar del expediente (en la propuesta de Resolución del expediente sancionador) se afirma que con ocasión de la actuación llevada a cabo por el Excelentísimo Ayuntamiento de Almería con objeto de la rehabilitación y acceso a los "refugios" en la Plaza Manuel Pérez García se ha producido una importante lesión al Patrimonio Histórico, es fundamental determinar la naturaleza y gravedad de los daños alegados sin perjuicio de valorar también la omisión de la vigilancia y cautela de la Administración Autonómica pues se estaría generando una doble y respectiva responsabilidad, de la Comunidad Autónoma y Ayuntamiento. 
En el Proyecto de Seguimiento Arqueológico de estas obras se concluye que existe una cierta afección sobre el Patrimonio arqueológico causada por las remociones de tierra necesarias para la construcción de un ascensor que permita el acceso a los "refugios" de la Guerra Civil existentes en la Plaza Manuel Pérez García. También se añade que la intervención arqueológica tiene como objetivo documentar los restos arqueológicos dejados al descubierto en la citada obra, y evitar la destrucción de aquellos otros restos arqueológicos que pudieran verse afectados por la obra aún sin realizar. Es manifiesto y así es constatado por sendas intervenciones previas de los arqueólogos oficiales, que se observan -a nivel superficial- restos arqueológicos. Sin embargo, en un primer momento cobra presencia la incertidumbre frente a su identificación. Según la arqueóloga de la Delegación Provincial de Cultura, los restos arqueológicos que se observan son restos murarios similares a los que han aparecido en otras intervenciones arqueológicas realizadas en las inmediaciones, según palabras textuales "este hecho hace pensar que las estructuras pertenezcan a la Muralla de Jairán construida a comienzos del siglo XI". Es razonable pensar que el construir un acceso a los "refugios" (acceso que debe reunir todas las condiciones de seguridad que establece la normativa y que ha de garantizar una entrada y una evacuación adecuada al lugar y al momento) es una tarea ardua, no exenta de complicaciones cuando se tiene que construir o edificar una entrada o salida en una zona cubierta por una plaza que está plagada de restos arqueológicos en el subsuelo difícilmente de predecir dónde y cómo se ubican si no es tras una excavación inicial y un seguimiento arqueológico de la misma. Los daños alegados pueden considerarse daños inevitables en la realización de una excavación de esas características, como otros tantos lo han sido con ocasión de la construcción de la nueva ordenación espacial y de las obras de infraestructuras acaecidas en los siglos XIX y XX respectivamente. Es decir, el hecho de que los restos murarios estén ocultos en el subsuelo de la ciudad dificultan, por un lado, cualquier tarea que deba de hacerse y en la que éstos se vean afectados y, por otro, la correcta identificación de los restos hallados en un primer momento.

\subsubsection{La reversibilidad o no de los daños}

Otra disputa que sacude el análisis de los daños es el de su reversibilidad o no. Son los arqueólogos expertos en dilucidar en qué términos lo son en uno u otro sentido. Ello no es obstáculo para advertir que las opiniones de los arqueólogos intervinientes vertidas en sendos Informes no son coincidentes en este punto. En otro lugar de este Informe se pone de manifiesto que para llegar a una valoración equitativa, hubiese sido de gran utilidad la creación de una Comisión Mixta de expertos caracterizada básicamente por la realización 
de un trabajo coordinado y conjunto presidido por las opiniones de los arqueólogos oficiales y de otras consideraciones de expertos en la materia.

Aunque en los Informes posteriores a los seguimientos arqueológicos se confirmaron que los restos afectados por la obra se correspondían con el flanco izquierdo de la Puerta de Pechina perteneciente al sistema defensivo del siglo XI, no obstante, hay que hacer tres precisiones respecto a esta cuestión:

Primero, el sistema defensivo o murario de la ciudad se encuentra en una situación muy desigual. Los posibles daños provocados por las obras no se han producido sobre un bien incólume. En ambos Informes arqueológicos se expresa con rotundidad que la muralla presenta, con anterioridad a estas obras, un estado muy irregular al verse afectada por numerosas obras de infraestructura. Baste apuntar que el derribo de la muralla se produjo en la segunda mitad del siglo XIX dando lugar a nuevos espacios públicos como la Plaza Manuel Pérez García, donde se ubica el acceso al refugio. Asimismo se expone que al norte de la citada puerta hay zonas que prácticamente han desaparecido y las construcciones exteriores a la muralla están casi arrasadas ya que ocupan un espacio que hace unos años era calle abierta al tráfico.

Unida a la anterior hay que destacar otra consideración: el estado deleznable del mortero empleado en la construcción defensiva y que, según los Informes analizados, se deteriora con gran facilidad y ofrece problemas de fácil desprendimiento de las piedras a las que se adosa, y por consiguiente su limitado valor arqueológico.

Segundo, los daños ocasionados por las controvertidas obras son limitados. A tenor del Informe, se concretan en la destrucción de "parte" del lienzo de la muralla (que constituye el flanco izquierdo de la Puerta de Pechina) con una pérdida de 1,40 metros por 0,60 metros de anchura aproximadamente dentro del marco del sistema defensivo, y las conducciones de agua que han desaparecido en el lugar de la zona excavada aunque las no afectadas presentan un buen estado de conservación.

Tercero, precisamente el calificar a los daños originados como pérdida "parcial" de la muralla es lo que puede implicar la reconstrucción de esa parte afectada. Si bien, es imposible restituir la muralla completamente a su estado originario, ello no obsta para que se pueda rehacer si se consideran textualmente los Informes Arqueológicos -incluso el de la arqueóloga de la Delegación de Cultura- en los que se asegura que "la intervención ha permitido documentar parcialmente, ya que no se ha agotado la secuencia estrati- 
gráfica por tratarse sólo de un control de los movimientos de tierra, secciones parciales del lienzo que constituye el flanco izquierdo de la puerta...", lo que se complementa con la afirmación de que aunque las conducciones de agua han desaparecido totalmente en la zona excavada "su trazado e inclinación se puede reconstruir a partir de las secciones este y oeste de dicha excavación". Queda, pues, patente que la construcción muraria presenta una estructura secuencial que garantiza la posible reconstrucción de la parte afectada a partir de las secuencias todavía subsistentes y, además, se puede apuntar que la realización de esas controvertidas obras han ocasionado un daño que puede reconvertirse en un hallazgo para la ciudad de Almería. Por último hay que considerar que se han conservado los restos arqueológicos desprendidos por si, en un futuro, se decide dar continuidad a este sistema defensivo. Sobre esta polémica cabe preguntarse ¿qué se pretende? ¿consolidar un pequeño trozo de restos, más bien cimentar, y luego rehabilitar este mínimo sector a su estado del siglo XI o, quizás, seguir la excavación de todos los restos de muralla, demoliendo las actuales edificaciones, estructuras e infraestructuras de la Plaza, y reconstruir una moderna muralla que divida en dos los sectores de la ciudad en que habría de actuarse? En este sentido la Ley del Patrimonio de 1985 expresa que corresponden a los poderes públicos procurar por todos los medios la conservación, consolidación, mejora y rehabilitación de los bienes que integran el Patrimonio, evitando los intentos de reconstrucción salvo cuando se utilicen partes originales de los mismos y pueda probarse su autenticidad (artículo 39), como sucede en este caso.

\subsubsection{La sanción aplicada}

En este análisis no se puede obviar el examen de la sanción aplicada. A tenor del artículo 76.3.b) de la Ley del Patrimonio Histórico Español de 1985, las lesiones contra el Patrimonio Histórico, que sean constitutivas de la infracción administrativa tipificada en el artículo 76.1.e) de la misma Ley, serán sancionadas con multa de hasta 25.000 .000 de pesetas, entendiéndose por tanto desde 0,01 a 150.253,03 euros en la actualidad. En el caso que nos ocupa la Administración competente en Cultura, frente a la comisión de la infracción administrativa, ha decidido imponer una sanción de 120.000 euros al Ayuntamiento como responsable de la lesión causada a la Muralla de Jairán. La cuantía, determinada provisionalmente por la Delegación Provincial, se ha ratificado por la Consejería de Cultura en cuanto ostenta la competencia para imponer las multas pecuniarias de hasta 150.253,03 euros -entendiendo que deben superar los 60.101,21 euros, que es el límite máximo para que sancione el Director General de Bienes Culturales-. 
El principio de proporcionalidad, que debe inspirar el ejercicio de la potestad sancionadora administrativa, tampoco ha estado exento de disputa en esta ocasión. Según el artículo 131.3 de la Ley del Régimen Jurídico de las Administraciones Públicas y del Procedimiento Administrativo Común, en la imposición de sanciones la Administración Pública debe guardar la debida adecuación entre la gravedad del hecho que constituye la infracción y la sanción aplicada al responsable como consecuencia de aquélla. Para calcular la cuantía de la sanción, la Ley expresa los criterios de graduación.

Con independencia de cualquier otra conclusión emitida en este Informe, y considerando la discutible "todavía" naturaleza de los daños ocasionados, hay que añadir irremediablemente otras reflexiones que, muy probablemente, determinan la nulidad y, en todo caso, la reducción de la multa a una cantidad simbólica:

Primero, la ausencia del tercer criterio de graduación que incorpora el artículo 131.3.c) de la citada Ley de Procedimiento Administrativo de 1992. Es decir, la ausencia de reincidencia, por comisión de más de una infracción de la misma naturaleza en el término de un año y así haya sido declarado por Resolución firme.

Segundo, la ausencia de intencionalidad -del primer criterio del artículo 131.3- en las actividades realizadas por el Ayuntamiento y que originan la producción de unos daños no deseados sobre el Patrimonio Histórico. Como queda de manifiesto en la documentación presentada y en las actuaciones, cabe deducir que la Corporación Local no persigue otro interés que el poner en valor los "refugios" bélicos como complemento a la oferta turística almeriense en el propósito de incrementar el enriquecimiento económico de la zona centro de la ciudad. El único reproche cabe hacerlo desde el resultado que produce la celeridad de unas obras que a la postre suelen hacerse, en la mayoría de los casos, de una forma casi rutinaria en una ciudad como Almería.

Para terminar, es indiscutible la colaboración y disposición que muestra el Ayuntamiento de Almería en todo momento con la Delegación de Cultura, desde que es requerido inicialmente hasta la finalización del procedimiento sancionador. Esta actitud culmina con la anecdótica solicitud, por parte del Concejal Delegado, de subsanación de la notificación defectuosa realizada al anterior representante, y en la que advierte la imposibilidad de alegación alguna debido a la indeterminación de la cuantía propuesta como sanción notificada: 1.120,200 euros cuando en realidad parece que se quiso decir 120.000 
euros, por cuya razón podemos preguntar si la cuantía correcta es la primera 1.120,200 euros, siendo la segunda de 120.000 euros un error numérico o material.

Por último, también es destacable el efecto que produce la realización de los daños arqueológicos en la conducta posterior del Ayuntamiento, que le lleva a adoptar las siguientes medidas:

Primero, la protección de los daños siguiendo las cautelas que prescribe el colegiado Alcaraz Hernández. Para evitar el deterioro de los restos arqueológicos se propone cubrirlos con una malla transpirable y sobre ésta una capa de grava de un grosor no inferior a los cuarenta centímetros sobre el punto más elevado de las estructuras evitando el tránsito de maquinaria pesada sobre esta zona.

Segundo, la evidente disposición del Ayuntamiento para una futura reconstrucción del pequeño trozo de muralla, que se manifiesta en el depósito del veinte por ciento del importe que se contiene en el Proyecto de Seguimiento, y que supuso una modificación parcial del proyecto técnico correspondiente, aún cuando ello implica un incremento (superior a cien mil euros) del importe final del proyecto de obras citado.

Tercero, el planteamiento de una futura exposición del hallazgo (de los restos arqueológicos) que redunde en beneficio del conocimiento de todos los almerienses y turistas. Este proyecto ha sido galardonado con el "Reconocimiento Patrimonial" por el Club UNESCO de Pechina al Ayuntamiento de Almería por la puesta en valor histórico, social, turístico, monumental y cultural de los hallazgos arqueológicos de la "Puerta de Pechina".

La propuesta inicial del Ayuntamiento de exponer públicamente los restos arqueológicos hallados no le faltan tampoco apoyos legales ya que el preámbulo de la Ley del Patrimonio Histórico de Andalucía de 1991 dispone que si bien la Ley desarrolla los instrumentos necesarios para la tutela de nuestro Patrimonio Histórico, también es consciente de que la mejor garantía de su conservación y enriquecimiento es su adecuada difusión. Esta difusión corresponde al Ayuntamiento de Almería en la misión de realzar y dar a conocer el valor cultural de los bienes integrantes del Patrimonio Histórico Andaluz que radique en su término municipal tal y como manda el artículo 4, párrafo 1 de la misma Ley.

En definitiva, la iniciativa de exhibir los restos murarios hallados en la Plaza Manuel Pérez García supone una revalorización de esos restos y por tanto 
una optimización de los recursos, contribuyendo a un desarrollo turístico y a la consecución del fin último que proclama el artículo 2 de la Ley 16/1985, de 25 de julio, de proteger y transmitir a las generaciones futuras, el Patrimonio Histórico español.

No obstante no hay que dejar de subrayar que los daños alegados son mínimos y casuales nada comparables con los ocasionados en otras ciudades cercanas, como por ejemplo, lo sucedido en Málaga, cuando se destruyeron diversos restos arqueológicos para dar respuesta a una necesidad municipal en la construcción del aparcamiento de la Marina.

A la vista de la anterior exposición de antecedentes, así como de la normativa aplicable, se formulan las siguientes

\section{CONCLUSIONES:}

Primera: es una exigencia ineludible para la ciudad de Almería la recuperación de las construcciones de carácter subterráneas realizadas para la protección de la vida de los ciudadanos durante la Guerra Civil española (19361939), porque suponía la tutela de la vida de los habitantes como el más importante derecho fundamental.

Segunda: en consecuencia, son restos de extraordinaria importancia histórica, técnica, sociológica, antropológica, cultural, etc., constituyendo una obligación su mantenimiento y conservación, teniendo en cuenta el interés general que tales obras subterráneas tenían para la ciudad.

Tercera: es una labor importante la que realiza el Ayuntamiento de Almería para recuperar la Memoria Histórica, conservar y utilizar, desde el punto de vista cultural, los citados "refugios", realizada por este Ayuntamiento y costeada por el mismo según consta en la documentación que obra en el Archivo Municipal.

Cuarta: Aunque estas construcciones tienen "per se" la condición de "bienes de interés cultural", es obligatoria para las Administraciones Públicas la recuperación, restauración y conservación de las mismas "poniendo en valor" estos bienes históricos y culturales, no sólo para los ciudadanos de Almería sino para toda clase de visitantes españoles o extranjeros, con la consiguiente dimensión turística (vid. Apartado 1.6 de este Dictamen). 
Quinta: se considera correcto el procedimiento seguido por el Ayuntamiento de Almería para la "puesta en valor" de los "refugios" en el seno de la Comisión de Seguimiento del Plan de Dinamización Turística, y del consiguiente Convenio de Colaboración en el que participan el Ayuntamiento de Almería, la Secretaría de Estado de Comercio y Turismo del Ministerio de Economía, la Consejería de Turismo, Comercio y Deporte de la Junta de Andalucía y la Asociación Provincial de Empresarios de Hostelería de Almería, Comisión que decidió la referida "puesta en valor" por acuerdo unánime de 7 de febrero de 2005 (vid. Apartado 2.1 de este Dictamen), siendo aprobada la intervención arqueológica por la Delegación de Cultura de la Junta de Andalucía el 9 de mayo de 2005.

Sexta: la Administración Cultural de la Junta de Andalucía estimó que se habían producido ciertos daños en restos arqueológicos por lo que sancionó al Ayuntamiento de Almería; conducta de la Administración andaluza que no parece adecuada, según se argumenta en el texto de este Dictamen, y la cual no debe ser valorada ahora ya que se encuentra recurrida por el Ayuntamiento de Almería.

Séptima: existe una competencia concurrente entre la Administración de la Comunidad Autónoma y el Ayuntamiento de Almería puesto que la remoción de tierras se ha realizado a plena luz del día a la vista de las Administraciones competentes y de la propia ciudad, poniéndose de manifiesto por los informes arqueológicos que obran en el expediente el escaso valor arqueológico de los restos, sin olvidar las contradicciones que existen entre los técnicos.

Octava: se hace imprescindible, en todo caso, alegar la coordinación prevista en el artículo 103.1 de la Constitución y su desarrollo en el artículo 3.1 de la Ley 30/1992, sin olvidar los principios que la misma Ley consagra en su artículo 4, según el cual las Administraciones se relacionan y actúan "de acuerdo con el principio de lealtad institucional" y que desglosa el mismo artículo 4 en la obligación de prestar "la cooperación y asistencia activa que las otras Administraciones pudieran recabar para el eficaz ejercicio de sus competencias". Principios estos consolidados en la doctrina del Tribunal Constitucional y del Tribunal Supremo, a través de su reiterada jurisprudencia, entre otras en las Sentencias del Tribunal Constitucional 204/2002, de 31 de octubre, 181/1998, de 17 de septiembre, 132/1998, de 18 de junio, 36/1994, de 10 de febrero, 85/1993, de 8 de marzo, 27/1987, de 27 de febrero, y del Tribunal Supremo, entre otras, en la novedosa sentencia de 22 de noviembre de 2005 (Sala de lo Contencioso-Administrativo, Sección 4ª ${ }^{2}$. En la consecución de este objetivo se sugiere la urgente necesidad de suscribir un Convenio entre las 
dos Administraciones con competencia sobre los bienes que integran el Patrimonio Histórico de Almería para dar respuesta a las cuestiones que pudieran suscitarse sobre esta materia en un futuro.

Novena: el bien general de la sociedad exige que se produzca el acuerdo para conservar unos valores indiscutibles, atribuibles no sólo a la muralla sino también a los "refugios", de lo contrario estaríamos ante un conflicto de prevalencia de bienes. En este sentido, no puede olvidarse que los "refugios" tienen el carácter y la naturaleza de Bien de Interés Cultural "per se", sin necesidad de declaración específica y, en todo caso "ex abundantia cordis", procede la inmediata iniciación del procedimiento de declaración prevista en la Ley Estatal de 1985 y en la Ley Andaluza de 1991. Por tanto, hay que concluir que estos valores, ya reconocidos en otras ciudades españolas, se encuentran por encima de opiniones subjetivas, todas ellas muy interesantes, pero que han de condicionarse al interés de la Comunidad y al interés del Patrimonio Histórico que, en definitiva, constituyen el fin supremo de las Administraciones Públicas.

Esta es nuestra opinión en Derecho y que sometemos gustosamente a cualquier otro criterio jurídico mejor fundado que el nuestro.

Almería, mayo de 2006 